\title{
Association Study of Fat-mass and Obesity-associated Gene and Body Mass Index in Japanese Patients with Schizophrenia and Healthy Subjects
}

\author{
Shin-ya Watanabe ${ }^{1}$, Jun-ichi Iga ${ }^{1}$, Shusuke Numata ${ }^{1}$, Masahito Nakataki $^{1}$, Toshihito Tanahashi $^{2}$, Mitsuo Itakura $^{3}$, \\ Tetsuro Ohmori \\ ${ }^{1}$ Department of Psychiatry, Course of Integrated Brain Sciences, University of Tokushima School of Medicine, Tokushima, ${ }^{2}$ Division of \\ Gastroenterology, Department of Internal Medicine, Graduate School of Medicine, Kobe University, Kobe, ${ }^{3}$ Division of Genetic Information, \\ Institute of Genome Research, University of Tokushima, Tokushima, Japan
}

\begin{abstract}
Objective: Fat-mass and obesity-associated (FTO) gene is known to be involved in the pathophysiology of obesity and a single-nucleotide polymorphism (SNP) rs9939609 of FTO gene is repeatedly confirmed to be associated with body mass index (BMI) and obesity. The aim of this study is to elucidate effects of FTO gene polymorphism on BMl in Japanese patients with schizophrenia and healthy subjects.

Methods: Three hundred fifty one patients with schizophrenia and 342 age- and sex- matched healthy subjects participated in the study. Information on BMl and antipsychotic medication was also collected from patients and healthy subjects. Genotype of the FTO SNP rs9939609 was determined by TaqMan SNP Genotyping Assays.

Results: There was no significant difference in BMl between patients and healthy subjects. No significant difference in BMl was observed among any medications. We observed no significant difference in rs9939609 allele frequencies between patients and healthy subjects. There was a significant difference in BMl between healthy subjects with risk (AA or TA) genotypes and those with TT genotype. We also observed a significant positive correlation between the number of risk allele (A allele) and BMI in healthy subjects.

Conclusion: Our study suggested that FTO rs9939609 polymorphism might have some impacts on the BMl in healthy subjects, but might not have same impacts on the BMl of patients with schizophrenia
\end{abstract}

KEY WORDS: Fat-mass and obesity-associated; Body mass index; Schizophrenia; Gene association studies; Antipsychotics agents.

\section{INTRODUCTION}

Weight gain and obesity are frequent and serious adverse effects of some atypical antipsychotics which have been prescribed as the first line treatment for schizophrenia. Weight gain and obesity are also known to induce non-adherence to the treatment. Moreover, obesity caused by antipsychotics may shorten life expectancy of patients with schizophrenia by increasing the risk of cardiovascular disease. ${ }^{1)}$ Although the mechanism and predictor of metabolic abnormalities induced by antipsychotics are poorly understood, it has been proposed that some genetic variants

\footnotetext{
Received: June 7, 2012 / Revised: August 9, 2012

Accepted: August 10, 2012

Address for correspondence: Shin-ya Watanabe, MD Department of Psychiatry, Course of Integrated Brain Sciences, University of Tokushima School of Medicine, Kuramoto-cho 2-50-1, Tokushima 770-8503, Japan

Tel: +81-86-633-7130, Fax: +81-86-633-7131

E-mail: shinya550314@yahoo.co.jp
}

play a significant role in this process and make some patients more susceptible to weight gain. Candidate genes extensively investigated are related with the pharmacological action of atypical antipsychotics. For examples, polymorphisms of serotonin receptor $2 \mathrm{C}^{2-4)}$ and $2 \mathrm{~A}$ genes, ${ }^{3)}$ histamine receptor $\mathrm{H} 1$ gene, ${ }^{5}$ dopamine receptor $\mathrm{D} 2^{6,7)}$ and D4 genes, ${ }^{8)}$ adrenergic receptor $\alpha 2 \mathrm{~A}^{9)}$ and $\beta 3^{10)}$ genes have been explored. However, most of these studies have not identified any genetic polymorphism that accounts for a significant proportion of the inter-individual variability.

An alternative approach to investigate genetic factors associated with weight gain secondary to antipsychotic treatment is to explore genetic variants associated with obesity. Recent studies found new candidate genes associated with obesity in genome wide association studies. Particular interest is focused on the fat-mass and obesity-associated (FTO) gene. FTO is a gene located in chromosome region 16q12.2 and its function is still unknown. However, the single-nucleotide polymorphism (SNP)

(C) This is an Open-Access article distributed under the terms of the Creative Commons Attribution Non-Commercial License (http://creativecommons.org/licenses/by-nc/3.0) which permits unrestricted non-commercial use, distribution, and reproduction in any medium, provided the original work is properly cited. 
rs9939609 in the first intron of FTO gene was repeatedly confirmed to be associated with body mass index (BMI) and obesity in both adults and children. ${ }^{11,12)}$

The investigation about association between FTO gene polymorphism and obesity in patients with schizophrenia may help to reveal the mechanism of weight gain induced by antipsychotics. The aim of our study is to elucidate the relationships among FTO gene polymorphism (rs9939609) and BMI in Japanese patients with schizophrenia and healthy subjects.

\section{METHODS}

\section{Subjects}

We recruited patients with schizophrenia from 12 psychiatric hospitals in Tokushima, Japan. All patients were diagnosed as schizophrenia according to Diagnostic and Statistical Manual of Mental Disorders, fourth edition (DSM-IV) criteria on the basis of extensive clinical interviews by two trained psychiatrists and a review of medical records, and underwent medical, neurologic, psychological and laboratory evaluation before participating in this study. We also recruited age- and sex- matched healthy Japanese volunteers. For the genetic studies, we obtained genomic DNA samples from the participants. Body weight and height of all subjects were measured and BMI was calculated as weight in kilograms divided by the square of the height in meters. All participants provided written informed consent and the institutional ethics committees approved our genetic association studies (IRB approval number: H20-1).

\section{Genetic Analysis}

We isolated genomic DNA from peripheral leukocytes using commercially available kit (Qiagen, Hilden, Germany). Genotype of the FTO SNP rs9939609 was determined by TaqMan SNP Genotyping Assays (Applied Biosystems, Foster City, CA, USA) according to the protocol recommended by the manufacturer. FTO gene polymorphism (rs9939609) was selected as a candidate polymorphism

Table 1. Demographic data of patients with schizophrenia and healthy subjects

\begin{tabular}{lccl}
\hline characteristic & Data & Healthy subject & $p$ value \\
\hline Male & 224 & 228 & \\
Female & 127 & 115 & 0.463 \\
Age (year) & $52.32 \pm 13.744$ & $50.68 \pm 11.621$ & 0.092 \\
BMl (kg/m $\left.{ }^{2}\right)$ & $23.86 \pm 4.017$ & $23.38 \pm 2.753$ & 0.071 \\
\hline
\end{tabular}

Values are presented as number or mean \pm standard deviation. based on previous reports showing a significant genetic association with BMI and obesity. ${ }^{11,12)}$

\section{Statistical Analysis}

All analyses were performed with SPSS 14.0 (SPSS Inc., Chicago, IL, USA). We compared the allele frequency of patients and healthy subjects using the chisquare tests. Unpaired t-test was performed to compare BMI between the carriers of TT genotype and the carriers of AA or AT genotype in patients and healthy subjects respectively. We examined the correlation between the number of risk allele (A allele) of rs9939609 SNP and BMI using linear regression analysis. We set statistical significance at $p<0.05$ for all tests.

\section{RESULTS}

\section{Participants}

We included 351 schizophrenia patients (224 men and 127 women; mean age 52.32 years, standard deviation [SD] 13.74 years; mean BMI $23.86 \mathrm{~kg} / \mathrm{m}^{2}$, SD 4.01 $\mathrm{kg} / \mathrm{m}^{2}$ ), and 343 healthy subjects (228 men and 115 women; mean age 50.68 years, SD 11.62 years; mean BMI $23.38 \mathrm{~kg} / \mathrm{m}^{2}, \mathrm{SD} 2.75 \mathrm{~kg} / \mathrm{m}^{2}$ ). The characteristics of patients and healthy subjects are shown in Table 1 . There was no significant difference in BMI between patients and healthy subjects. Information about medication in 346 patients was available. Most patients (62.4\%) were treated with poly-pharmacy. No significant difference in BMI was observed among any medications (Fig. 1).

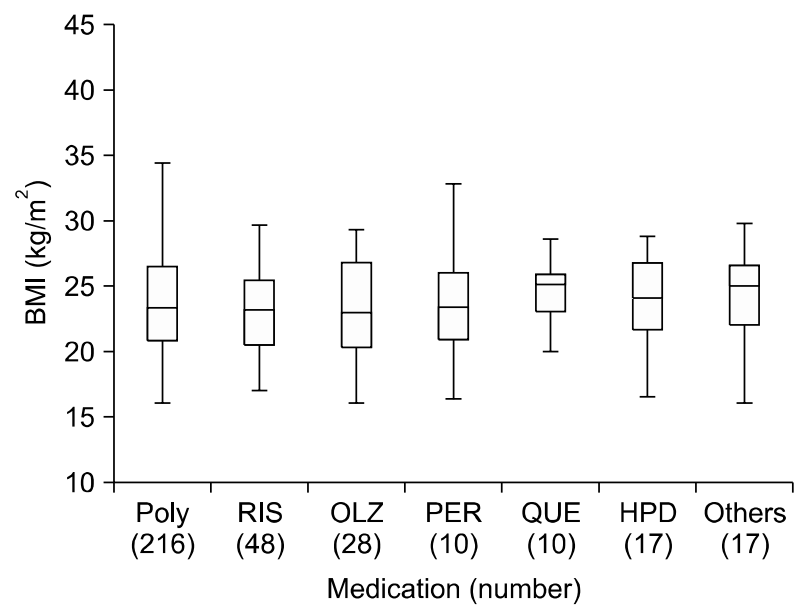

Fig. 1. Most patients (62.4\%) were treated with poly-pharmacy. No significant difference in body mass index (BMI) was observed among any medications. Poly, polypharmacy; RIS, risperidone; OLZ, olanzapine; PER, perospirone; QUE, quetiapine; HPD, haloperidol. 


\section{Single Nucleotide Polymorphism and Schizophrenia}

Allele frequencies of each group are shown in Table 2. We observed no significant difference in rs9939609 allele frequencies between patients and healthy subjects.

\section{Single Nucleotide Polymorphism and Body Mass Index}

There was a significant difference in BMI between the carriers of AA/AT genotype and the carriers of TT genotype in healthy subjects. The carriers of AA/AT genotype had significant higher BMI than those of TT genotype in healthy subjects (Fig. 2) and a significant positive correlation was observed between the number of A allele and BMI in healthy subjects (Fig. 3). However, there was no significant difference in BMI between the carriers of AA/AT genotypes and those of TT genotype in patients (Fig. 4).

\section{DISCUSSION}

This study is the first study about the association between genotype of FTO rs9939609 polymorphism and schizophrenia. There are two major findings in this study.

Table 2. The association between genotype of FTO rs9939609 polymorphism and schizophrenia

\begin{tabular}{lcccc}
\hline \multirow{2}{*}{ rs9939609 group } & \multirow{2}{*}{ Number } & \multicolumn{2}{c}{ Allele } & \multirow{2}{*}{$p$ value } \\
\cline { 3 - 4 } & & T allele & A allele & \\
\hline Patient & 351 & 576 & 126 & \\
Healthy subject & 343 & 553 & 133 & 0.491
\end{tabular}

There was no significant difference in rs9939609 allele frequencies between patients and healthy subjects. FTO, foot mass and obesity-associated gene.

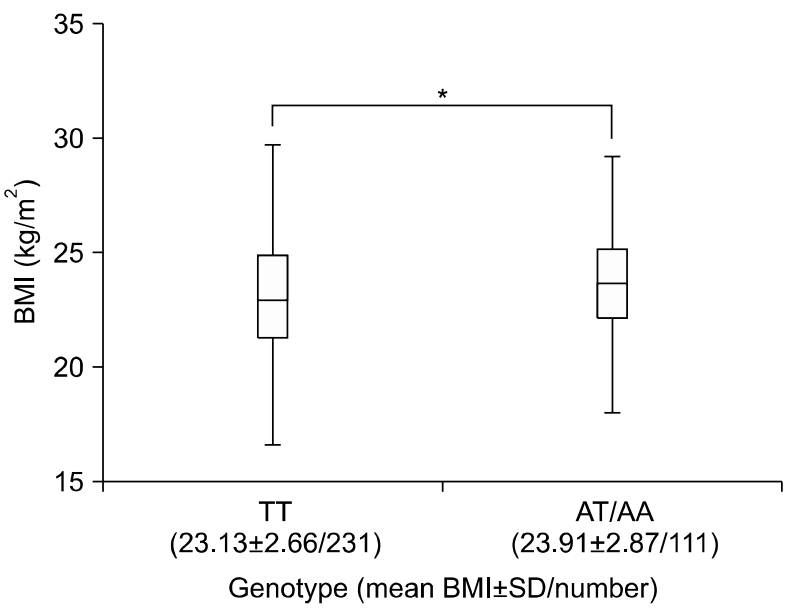

Fig. 2 The carriers of AA/AT genotypes had significant higher body mass index (BMI) than those of $\Pi$ genotype in healthy subjects $(p=0.017) .{ }^{*} p<0.05 . S D$, standard deviation.
First, we did not observed significant association between genotype of FTO rs9939609 polymorphism and schizophrenia. This result is consistent with some genome-wide association studies about Japanese schizophrenia. ${ }^{13,14)}$ Similar to the results reported by Tabara et al. $(17.4 \%)^{15)}$ and the data in HapMap for Japanese population (Japanese in Tokyo [JPT]; 18.4\%), the rs9939609 A allele frequency was substantially lower in our study as compared with the European populations (18.7\% vs. $46 \%)$. Thus, we compared BMI between the carriers of AA/AT genotype and those of TT genotype in patients and healthy subjects respectively.

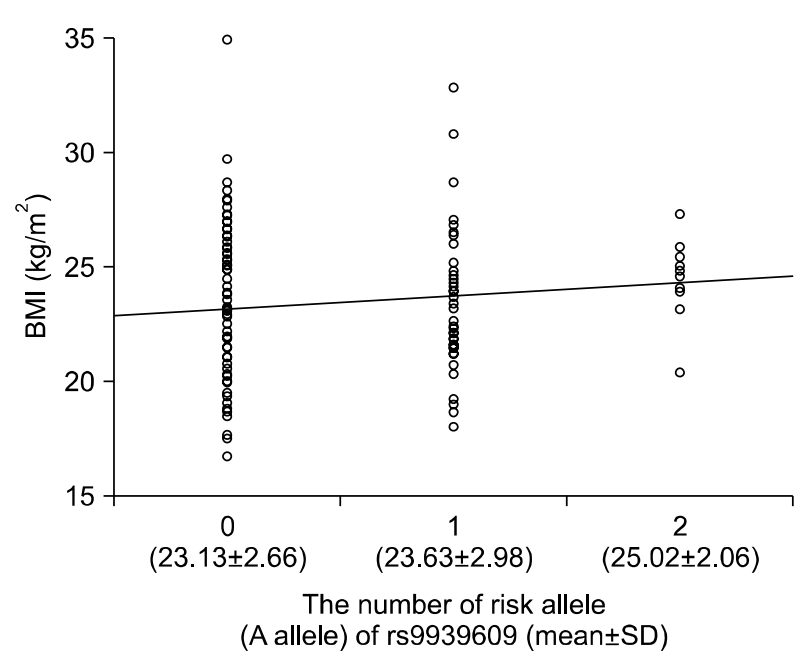

Fig. 3. Significant correlation between the number of $A$ allele of rs9939609 SNP and body mass index (BMI) in healthy subjects ( $p=0.002$, $\left.R^{2}=0.028\right) . S D$, standard deviation.

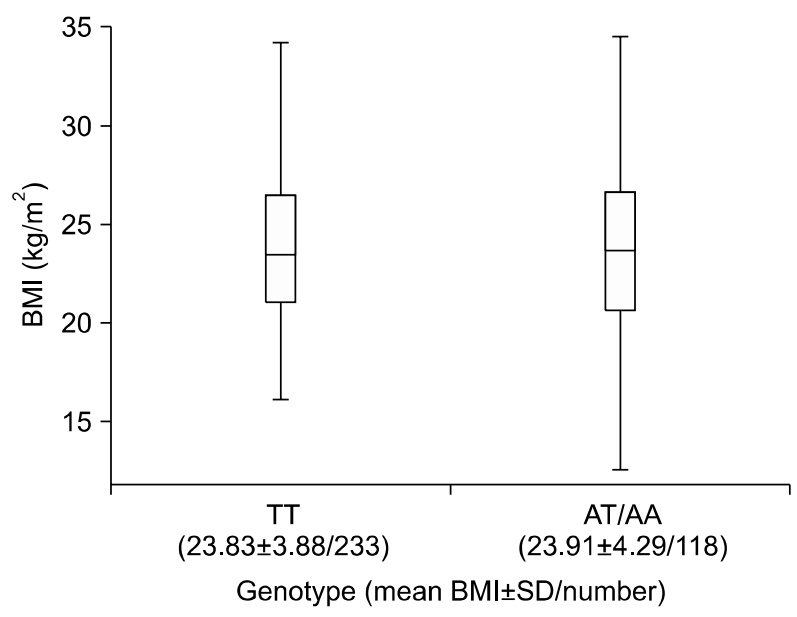

Fig. 4. There was no significant difference in body mass index (BMI) between the carriers of TT genotype and those of AA/AT genotype in schizophrenia $(p=0.851)$. SD, standard deviation. 
Second, we found a significant difference in BMI between the carriers of AA/AT genotype and those of TT genotype in healthy subjects. The carriers of AA/AT genotype had significant higher BMI than those of TT genotype in healthy subjects and a significant positive correlation was observed between the number of risk allele (A allele) and BMI in healthy subjects. Our results suggested that A allele increased BMI in healthy subjects and this result is consistent with previous studies in a Japanese population. ${ }^{15,16)}$ FTO gene is highly expressed in the arcuate nucleus ofthe hypothalamus and its expression is regulated by fasting and feeding in mice, ${ }^{17}$ indicating functional involvement of the FTO gene in the central control of energy homeostasis. ${ }^{18)}$ Although the function of SNP rs9939609 is still unknown, the number of risk allele may influence the central control of energy homeostasis and body weight in healthy subjects.

On the other hand, we could not observe a significant effect of A allele on BMI in patients with schizophrenia. Consistent with our result, recent report revealed that FTO rs9939609 polymorphism did not show a significant effect on antipsychotic-associated weight gain. ${ }^{19)}$ It is suggested that the medications and lifestyle modifications such as physical activity or diet could overcome the genetic predisposition to obesity in patients with schizophrenia . ${ }^{20,21)}$ As most of our patients were hospitalized for long periods and their food intake and exercise were managed according to the institution's rule, environmental interventions could overcome the genetic susceptibility conferred by the FTO genotype.

Our research has some limitations. First, the sample size is relatively small and larger studies and meta-analyses are needed to confirm these associations. Second, our study is cross-sectional and we could not examine the change of BMI during each antipsychotic treatment. Although we could not find significant differences in BMI among any antipsychotics, this result might be influenced by selection bias. For example, patients who had much weight before treatment might not be treated with the antipsychotics known to be associated with weight gain. Third, environmental factors which could contribute to the weight gain such as diet, physical activity were not examined. It is possible that the institutional differences in the access for food and exercise may influence our results. Taking these limitations into account, further investigations are warranted to understand the genetic risk of weight gain induced by antipsychotics.

\section{Acknowledgments}

This work was supported by a Grants-in-Aid for Scientific Research from the Japanese Ministry of Education, Culture, Sports, Science and Technology and by Japan Science and Technology Agency, CREST.

\section{REFERENCES}

1. Casey DE, Haupt DW, Newcomer JW, Henderson DC, Sernyak MJ, Davidson M, et al. Antipsychotic-induced weight gain and metabolic abnormalities: implications for increased mortality in patients with schizophrenia. J Clin Psychiatry 2004;65(Suppl 7):4-18.

2. De Luca V, Mueller DJ, de Bartolomeis A, Kennedy JL. Association of the HTR2C gene and antipsychotic induced weight gain: a meta-analysis. Int $J$ Neuropsychopharmacol 2007:10:697-704.

3. Gunes A, Melkersson KI, Scordo MG, Dahl ML. Association between HTR2C and HTR2A polymorphisms and metabolic abnormalities in patients treated with olanzapine or clozapine. J Clin Psychopharmacol 2009;29:65-68.

4. Sicard MN, Zai CC, Tiwari AK, Souza RP, Meltzer HY, Lieberman JA, et al. Polymorphisms of the HTR2C gene and antipsychotic-induced weight gain: an update and metaanalysis. Pharmacogenomics 2010;11:1561-1571.

5. Hong CJ, Lin CH, Yu YW, Chang SC, Wang SY, Tsai SJ. Genetic variant of the histamine-1 receptor (glu349asp) and body weight change during clozapine treatment. Psychiatr Genet 2002;12:169-171.

6. Hong CJ, Liou YJ, Bai YM, Chen TT, Wang YC, Tsai SJ. Dopamine receptor D2 gene is associated with weight gain in schizophrenic patients under long-term atypical antipsychotic treatment. Pharmacogenet Genomics 2010;20:359366.

7. Lencz T, Robinson DG, Napolitano B, Sevy S, Kane JM, Goldman D, et al. DRD2 promoter region variation predicts antipsychotic-induced weight gain in first episode schizophrenia. Pharmacogenet Genomics 2010;20:569-572.

8. Popp J, Leucht S, Heres S, Steimer W. DRD4 48 bp VNTR but not 5-HT 2C Cys23Ser receptor polymorphism is related to antipsychotic-induced weight gain. Pharmacogenomics $J$ 2009;9:71-77.

9. Park YM, Chung YC, Lee SH, Lee KJ, Kim H, Byun YC, et al. Weight gain associated with the alpha2a-adrenergic receptor-1,291 C/G polymorphism and olanzapine treatment. Am J Med Genet B Neuropsychiatr Genet 2006;141B: 394-397.

10. Ujike H, Nomura A, Morita Y, Morio A, Okahisa Y, Kotaka $\mathrm{T}$, et al. Multiple genetic factors in olanzapine-induced weight gain in schizophrenia patients: a cohort study. J Clin Psychiatry 2008;69:1416-1422.

11. Dina C, Meyre D, Gallina S, Durand E, Körner A, Jacobson $\mathrm{P}$, et al. Variation in FTO contributes to childhood obesity and severe adult obesity. Nat Genet 2007;39:724-726.

12. Frayling TM, Timpson NJ, Weedon MN, Zeggini E, Freathy $\mathrm{RM}$, Lindgren $\mathrm{CM}$, et al. A common variant in the FTO gene is associated with body mass index and predisposes to childhood and adult obesity. Science 2007;316:889-894.

13. Ikeda M, Aleksic B, Kinoshita Y, Okochi T, Kawashima K, Kushima I, et al. Genome-wide association study of schizophrenia in a Japanese population. Biol Psychiatry 2011;69: 472-478.

14. Yamada K, Iwayama Y, Hattori E, Iwamoto K, Toyota T, 
Ohnishi T, et al. Genome-wide association study of schizophrenia in Japanese population. PLoS One 2011;6:e20468.

15. Tabara $\mathrm{Y}$, Osawa H, Guo H, Kawamoto R, Onuma H, Shimizu I, et al. Prognostic significance of FTO genotype in the development of obesity in Japanese: the J-SHIPP study. Int J Obes (Lond) 2009;33:1243-1248.

16. Karasawa S, Daimon M, Sasaki S, Toriyama S, Oizumi T, Susa $\mathrm{S}$, et al. Association of the common fat mass and obesity associated (FTO) gene polymorphism with obesity in a Japanese population. Endocr J 2010;57:293-301.

17. Fredriksson R, Hägglund M, Olszewski PK, Stephansson O, Jacobsson JA, Olszewska AM, et al. The obesity gene, FTO, is of ancient origin, up-regulated during food deprivation and expressed in neurons of feeding-related nuclei of the brain. Endocrinology 2008; 149:2062-2071.

18. Cecil JE, Tavendale R, Watt P, Hetherington MM, Palmer
CN. An obesity-associated FTO gene variant and increased energy intake in children. $N$ Engl J Med 2008;359:25582566.

19. Perez-Iglesias R, Mata I, Amado JA, Berja A, GarciaUnzueta MT, Martínez García O, et al. Effect of FTO, $S H 2 B 1, L E P$, and LEPR polymorphisms on weight gain associated with antipsychotic treatment. J Clin Psychopharmacol 2010;30:661-666.

20. Johnson L, van Jaarsveld CH, Emmett PM, Rogers IS, Ness AR, Hattersley AT, et al. Dietary energy density affects fat mass in early adolescence and is not modified by FTO variants. PLoS One 2009;4:e4594.

21. Vimaleswaran KS, Li S, Zhao JH, Luan J, Bingham SA, Khaw KT, et al. Physical activity attenuates the body mass index-increasing influence of genetic variation in the FTO gene. Am J Clin Nutr 2009;90:425-428. 